\title{
Severe Short Stature: an unusual finding in lipoid proteinosis
}

\author{
Şükran Poyrazoğlu, Hülya Günöz, Feyza Darendeliler \\ Istanbul University, Istanbul Faculty of Medicine, Department of Pediatrics, Pediatric Endocrinology Unit, Istanbul, Turkey
}

\section{Keywords: \\ Genodermatosis, lipoid proteinosis, short stature, endocrinological evaluation \\ Received: 20 October, 2008 Accepted: 28 November, 2008 \\ Corresponding Author: Şükran Poyrazoğlu İstanbul University, İstanbul Faculty of Medicine, Department of Pediatrics, Pediatric Endocrinology Unit, İstanbul, Turkey Tel: +90-212-5324233 Fax: +90-212-533 1383 E-mail: sukranpoyrazoglu@yahoo.com}

\begin{abstract}
Lipoid proteinosis (LP) is a rare disorder and it can affect every organ in the body. The clinical manifestations of LP may vary considerably between affected individuals. Short stature is reported in patients with LP however the underlying etiology is not clear. Short stature may be due to endocrine dysfunction caused by deposition of hyaline-like material in endocrine glands. We investigated a 13 year old patient with LP (507 delT mutation) who had severe short stature. He had hoarseness since the age of one year, followed by characteristic skin lesions for LP and short stature. There was no pathology with respect to endocrinological investigations in our patient including growth hormone-IGF axis. Our results show that short stature in LP can not be explained by endocrinological abnormalities. Short stature may be an intrinsic component of the syndrome.
\end{abstract}

Conflict of interest: None declared

\section{INTRODUCTION}

Lipoid proteinosis (LP) is a condition characterized by the deposition of periodic acid Schiff-positive hyaline-like material in various tissues including skin, mucous membranes and internal organs. $(1,2)$ The etiology of LP is currently unknown. It has been shown that LP results from mutations in extracellular matrix protein 1 (ECM1) genes on chromosome 1q21. Although classical features include laryngeal infiltration leading to hoarseness, scarring and infiltrations of the skin, LP can affect every organ in the body. $(1,2)$ Recurrent episodes of inflamed parotid and submandibular glands may occur. A shortened tongue with a thickened frenulum may also be se- en.(3) Other extracutaneous features include epilepsy and neuropsychiatric abnormalities, sometimes in association with calcifications in the temporal lobes or in the hippocampus. $(4,5)$ Deposition of hyalinelike material in the eye may cause corneal opacities or secondary glaucoma. Intestinal bleeding may occur as a result of deposition in the small bowel. $(6,7)$ Lung and bronchial involvement has also been reported in patients with LP.(8) Insulin resistance was also detected.(9) Chakrabarti et al.(10) reported a patient with LP and dwarfism. The cause of dwarfism could not be elicited in this patient and it was postulated that the short stature could have been due to defective osteoblasts which are biologically similar to fibroblasts. En- 
docrinological dysfunction was not evaluated in this patient. Recently, short stature was reported in two LP patients from two different families.(11) Considering the possibility that short stature in LP patients may be due to endocrine dysfunction caused by deposition of hyaline-like material in endocrine glands, we investigated one of the patients reported below (Patient 1) for endocrinological involvement.

\section{CASE REPORTS}

Patient 1. A 13-year-old boy had been referred to our clinic with a history of hoarseness since the age of one year, followed by skin lesions and short stature. He was the offspring of a second degree consanguineous marriage. His height was $128.2 \mathrm{~cm}$, weight $25.9 \mathrm{~kg}$ and body mass index 15.8. Expressed as standard deviation scores (SDS), these values were -3.9 SDS, -3.1 SDS and -1.6 SDS respectively, according to age and sex specific Turkish standards.(12, 13) Sitting height/height ratio was normal for age (0.52). Mother's height was $168.5 \mathrm{~cm}$ (0.9 SD) and father's height was $175.1 \mathrm{~cm}(-0.2 \mathrm{SD})$. Physical examination revealed multiple acneiform scars on the face; beaded papules on the margins of the eyelids; papulovesicular lesions, scars and skin hyperkeratosis on the hands, elbows, knees, axilla and buttocks (Figure 1). Scarring was reported following trauma or injury. The cutaneous changes were unrelated to sun exposure. The patient's tongue was firm, thick, pale, with yellowish-white papules on its surface. The mobility of the tongue was restricted by a thickened frenulum. Dentition was normal. There were no signs of puberty. Developmental milestones were normal.

Routine blood chemistry, lipid profile, complete blood count, urine analysis and stool examination were all within the normal ranges. Bone age corresponded to age 10 years, according to the Greulich and Pyle method.(14) The electroencephalogram was normal. Further investigations were undertaken to detect deposition of hyaline-like material at various sites. Fundoscopic and slit lamp examination of the eyes revealed normal results. Laryngoscopic examination showed mucosal thickening in the vocal cords and subglottic region. Serum levels of vitamin A, zinc and copper were normal.

Hoarseness and characteristic skin changes of the patient was pathognomonic for LP. Histopathological examination of skin biopsy specimen showed orthokeratotic hyperkeratosis and acanthosis of epidermis, hyperkeratosis, acanthosis and evident bunch of collagen arranged in parallel to surface, and tight and fibrotic appearance of dermis and ectasia of some small blood vessels, some hyaline material deposition and hyaline appearance of basal lamina and fibrosis of papillary dermis.

The results of endocrinological investigations are shown in Table 1. Serum levels of

Figure 1: Multiple acneiform scars on face and beaded papules on the margins of eyelids (a), papulovesicular lesions, scars and hyperkeratosis on hands (b), elbows and buttocks (c) of lipoid proteinosis patient with short stature.
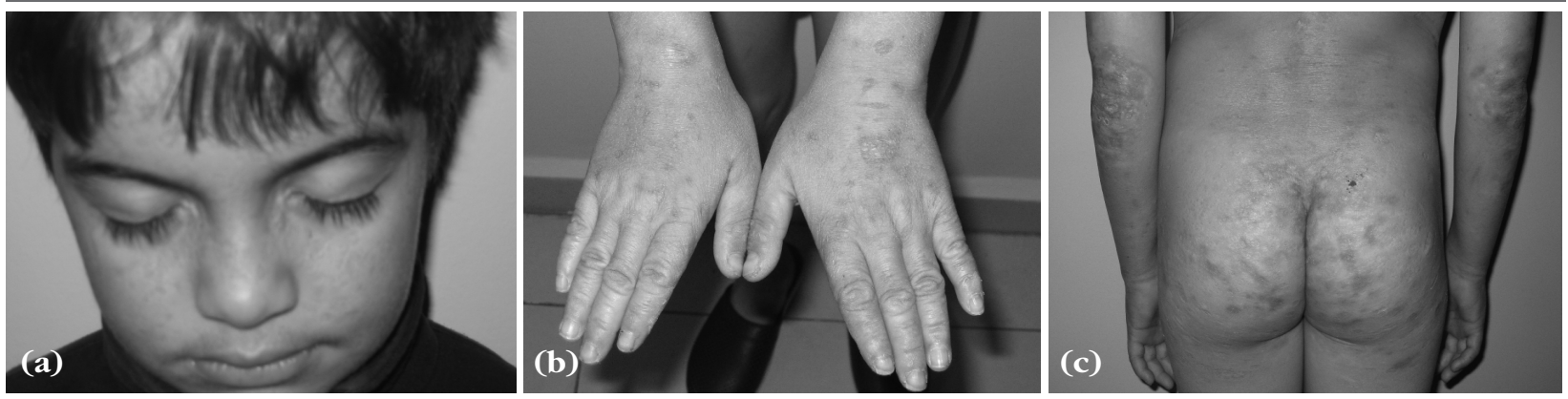
Table 1: Results of endocrinological investigations in Patient 1.

Thyroid hormone

- Free thyroxine

- Thyroid stimulating hormone

Insulin like growth factor-I (IGF-I)

IGF binding protein-3 (IGFBP-3)

Screening tests for growth hormone

deficiency (with sex steroid)

- Clonidine stimulation test

- Insulin stimulation test (ITT)

IGF-I generation test

\section{Cortisol}

- Basal

- at 60. minute of ITT

Prolactin

Oral glucose tolerance test

- Glucose (mg/dL)

- Insulin (mU/L)

Gonadotropin-releasing hormone test

- Follicle-stimulating hormone (IU/L)

- Luteinising hormone (IU/L)

Testosterone

Short human chorionic gonadotropin test

(1500 IU/m² per day - 3 days)

- Testosterone

thyroid hormone, insulin like growth factorI (IGF-I) and IGF-binding protein-3 (IGFBP3) were normal. Growth hormone (GH) secretion investigated by $\mathrm{GH}$ tests and sensitivity investigated by IGF-1 response to GH injection did not reveal GH deficiency or GH insensitivity. Adrenal cortex function was also normal at insulin tolerance test. Gonadotropin-releasing hormone test and testosterone response to human chorionic gonadotropin (HCG) stimulation were within normal ranges for age and pubertal status, indicative of a normally functioning hypothalamo-pituitary-gonadal axis.

Oral glucose tolerance test, performed for evaluation of insulin resistance, revealed normal results. Magnetic scanning showed calcification in both amygdals. Pituitary gland imaging results were unremarkable.
$19.8 \mathrm{pmol} / \mathrm{L}(\mathrm{N}: 12-24)$

$2.2 \mathrm{mIU} / \mathrm{L}(\mathrm{N}: 0.4-5.5)$

$96.1 \mathrm{ng} / \mathrm{mL}(\mathrm{N}: 76-278)$

$2328.9 \mathrm{ng} / \mathrm{mL}(\mathrm{N}: 2200-5900)$

Peak growth hormone response

$19.4 \mathrm{ng} / \mathrm{mL}$

$7.3 \mathrm{ng} / \mathrm{mL}$

Delta IGF-I: $200 \mathrm{ng} / \mathrm{mL}$

Delta IGFBP-3: 1220 ng/mL

$6.9 \mu \mathrm{gl} / \mathrm{dL}(\mathrm{N}: 5-15)$

$21.4 \mu \mathrm{gl} / \mathrm{dL}(\mathrm{N}>18)$

$13.7 \mathrm{ng} / \mathrm{mL}(\mathrm{N}: 3-18)$

$\begin{array}{lllll}0^{\prime} & 30^{\circ} & 60^{\circ} & 90^{\circ} & 120^{\circ} \\ 66 & 126 & 101 & 85 & 82 \\ 3.8 & 80 & 46 & 30.6 & 16.9 \\ 0 & 30^{-} & 60^{\circ} & 90^{\circ} & \\ 0.1 & 1.8 & 2.8 & 2.4 & \\ 0.8 & 2.8 & 5.3 & 6.2 & \end{array}$

$0.08 \mathrm{ng} / \mathrm{mL}$

Basal

After 3 days

$0.11 \mathrm{ng} / \mathrm{mL}$ $1.34 \mathrm{ng} / \mathrm{mL}$

For investigation of osteoblastic activity and bone turnover, bone mineral density of the lumbar L1-L4 vertebrae, serum levels of calcium, phosphorus and bone turnover markers were evaluated. The results were normal (Table 2). Endoscopic examination of the upper gastrointestinal tract and small bowel biopsy also gave normal results

Patient 2. The family history of Patient 1 revealed that one of his younger cousins (a 6 years old male) also had a hoarse voice and very mild cutaneous findings. On examination, this patient's height and weight were at the $10^{\text {th }}$ percentile for age. His mental development was normal. His parents were also first cousins.

Informed consent for genetic analysis was obtained from the families of both patients. The genetic analyses were performed 


\begin{tabular}{|c|c|}
\hline $\mathrm{Ca}(\mathrm{mg} / \mathrm{dL})$ & $9.4(\mathrm{~N}: 9.2-11)$ \\
\hline $\mathrm{P}(\mathrm{mg} / \mathrm{dL})$ & $4.3(\mathrm{~N}: 3.3-5.4)$ \\
\hline ALP (U/L) & $158(\mathrm{~N}: 150-390)$ \\
\hline Parathyroid hormone (pg/mL) & $32(\mathrm{~N}: 15-65)$ \\
\hline Osteocalcin (ng/mL) & $20(\mathrm{~N}: 0-21)$ \\
\hline $\begin{array}{l}\text { Urine dihidropyridinoline } \\
\text { (nmol dpol/mmol creatinine) }\end{array}$ & $3(\mathrm{~N}: 2.3-5.4)$ \\
\hline $\begin{array}{l}\text { Ll-L4 bone mineral density }\left(\mathrm{g} / \mathrm{cm}^{2}\right) \\
\text { Z-score }\end{array}$ & $\begin{array}{l}0.627 \\
-0.68(N>-2)\end{array}$ \\
\hline
\end{tabular}

in St John's Institute of Dermatology, London, UK. Both patients were homozygous for mutation 507delT in exon 6 of ECM1. Genetic analysis of the parents yielded a heterogeneous mutation 507delT in both parents of patient 1 and in the father of patient 2 .

\section{DISCUSSION}

LP results from mutations in ECM1, a glycoprotein expressed in several tissues including the skin. This glycoprotein is composed of two alternatively spliced isoforms, ECM1a and ECM1b, the latter lacking exon 7 of this 10-exon gene. The mutations map onto chromosome 1q21. To date, mutations that either affect ECM1a alone or that disturb both ECM1 transcripts have been demonstrated in several cases. Over 20 different mutations have been detected throughout the world.(1, 2) Exons 6 and 7 are the most common sites for ECM1 mutations in LP. Clinically, it appears that mutations outside exon 7 are usually associated with a slightly more severe mucocutaneous LP phenotype. Neurological features do not show any specific genotype-phenotype correlation. $(1,2)$

The clinical manifestations of LP may vary considerably between affected individuals. Individuals with the same genetic back- ground and the identical mutation were shown to have a vastly different phenotype. $(1,2)$ Homozygous 507 delT mutation was detected in our patients. Although both of our patients have the same mutation, the severity of disease was very different in the two patients. This particular mutation has been documented previously. Two Thai brothers with temporal lobe epilepsy and a 3-year-old Iranian male only with skin lesions and hoarseness were reported.(2) Uchida et al.(15) detected the same mutation in a patient with mucocutaneous lymphangiogenesis.

Chakrabarti et al.(10) reported a patient with LP and dwarfism. The cause of dwarfism could not be elicited in this patient and it was postulated that the short stature may have been be due to defective osteoblasts which are biologically similar to fibroblasts. Our patient also has short stature. However, his osteoblastic activity markers, bone turnover markers and bone mineral density were all normal.

Endocrinological investigations based on the possibility that short stature in LP patients may be due to endocrine dysfunction caused by deposition of hyaline-like material in the endocrine glands also failed to detect any endocrinological organ involvement.

Our results show that short stature in LP cannot be explained by endocrinological abnormalities. We postulate that short stature in LP patients probably constitutes one of the components of this rare syndrome with a hitherto unknown etiology. Further cases with short stature, if any, will enlighten this association.

\section{ACKNOWLEDGEMENT}

Sequencing of the ECM1 gene was kindly performed by Dr Lu Liu and Professor John McGrath, St John's Institute of Dermatology, London, UK.

\section{REFERENCES}

1. Chan I, Liu L, Hamada T, Sethuraman G, McGrath JA. The molecular basis of lipoid proteinosis: mutations in extracellular matrix protein 1. Exp Dermato/ 2007; 16:881-890. [Abstract / Full Text / PDF] 
2. Hamada T, Wessagowit V, South AP, Ashton GHS, Chan I, Oyama N, Siriwattana A, Jewhasuchin P, Charuwichitratana S, Thappa DM, Lenane P, Krafchik B, Kulthanan K, Shimizu H, Kaya TI, Erdal ME, Paradisi M, Paller AS, Seishima M, Hashimoto T, McGrath JA. Extracellular Matrix Protein 1 Gene (ECM1) Mutations in Lipoid Proteinosis and Genotype-Phenotype Correlation. J Invest Dermatol 2003;120:345-350. [Abstract / Full Text / PDF]

3. Aroni K, Lazaris AC, Papadimitriou K, Paraskevakou H, Davaris PS. Lipoid proteinosis of the oral mucosa: case report and review of the literature. Pathol Res Pract 1998;194:855-859. [Abstract]

4. Friedman L, Mathews RD, Swanepoel PD. Radiographic and computed tomographic findings in lipid proteinosis. A case report. S Afr Med J 1984;65:734-735. [Abstract]

5. Kleinert R, Cervos-Navarro J, Kleinert G, Walter GF, Steiner H. Predominantly cerebral manifestation in Urbach-Wiethe's syndrome (lipoid proteinosis cutis et mucosae): a clinical and pathomorphological study. Clin Neuropathol 1987;6:43-45. [Abstract]

6. Dinakaran S, Desai SP, Palmer IR, Parsons MA. Lipoid proteinosis: clinical features and electron microscopic study. Eye 2001; 15:666-668. [Abstract]

7. Caccamo D, Jaen A, Telenta M, Varela E, Tiscornia O. Lipoid proteinosis of the small bowel. Arch Pathol Lab Med 1994;118:572-574. [Abstract]

8. Al-Bitar Y, Samdani AJ. Lipoid proteinosis in two brothers with multiple organ involvement from Saudi Arabia. Int J Dermatol 2004;43:360-361. [Abstract / Full Text / PDF]

9. Kurtoglu S, Atabek ME, Adal E, Pirgon O. Insulin resistance in two adolescent siblings with lipoid proteinosis. Int J Dermatol 2007;46:543-545. [Abstract / Full Text / PDF]

10. Chakrabarti K, Sengupta SK, Ghosh AK, Das SK. Lipoid proteinosis (Urbach-Wiethe syndrome) with dwarfism. Indian Pediatr 1991; 28:75-78. [Abstract]

11. Baykal C, Topkarci Z, Yazganoglu D, Azizlerli G, Baykan B. Lipoid proteinosis: a case series from Istanbul. Int J Dermatology 2007; 46:1011-1016. [Abstract / Full Text / PDF]

12. Neyzi O, Furman A, Bundak R, Gunoz H, Darendeliler F, Bas F. Growth references for Turkish children aged 6 to 18 years. Acta Paediatr 2006;95:1635-1641. [Abstract]

13. Bundak R, Furman A, Gunoz H, Darendeliler F, Bas F, Neyzi O. Body mass index references for Turkish children. Acta Paediatr 2006;95:194-198. [Abstract]

14. Greulich WW, Pyle SI Radiographic atlas of skeletal development of the hand and wrist. 2nd ed. Standford, CA: Stanford University Press 1959.

15. Uchida T, Hayashi H, Inaoki M, Miyamoto T, Fujimoto W. A failure of mucocutaneous lymphangiogenesis may underlie the clinical features of lipoid proteinosis. Br J Dermatol 2007;156:152-157. [Abstract] 